\title{
Bonding All-Ceramic Restorations with Two Resins Cement Techniques: A Clinical Report of Three-Year Follow-Up
}

\author{
Rodolfo Bruniera Anchieta ${ }^{a}$ \\ Eduardo Passos Rocha ${ }^{a}$ \\ Erika Oliveira de Almeida ${ }^{a}$ \\ Amilcar Chagas Freitas Juniora \\ Ana Paula Martini
}

\section{ABSTRACT}

Ceramics have been widely used for esthetic and functional improvements. The resin cement is the material of choice for bonding ceramics to dental substrate and it can also dictate the final esthetic appearance and strength of the restoration. The correct use of the wide spectrum of resin luting agents available depends on the dental tooth substrate. This article presents three-year clinical results of a 41 years old female patient B.H.C complaining about her unattractive smile. Two all-ceramic crowns and two laminates veneers were placed in the maxillary incisors and cemented with a self-adhesive resin luting cement and conventional resin luting cement, respectively. After a three-year follow-up, the restorations and cement/teeth interface were clinically perfect with no chipping, fractures or discoloration. Proper use of different resin luting cements shows clinical appropriate behavior after a three-year follow-up. Self-adhesive resin luting cement may be used for cementing all-ceramic crowns with high predictability of success, mainly if there is a large dentin surface available for bonding and no enamel at the finish line. Otherwise, conventional resin luting agent should be used for achieving an adequate bonding strength to enamel. (Eur J Dent 2011;5:478485)

Key words: Conventional resin luting agent; Self-adhesive resin luting cement; Dental ceramic.

a Sao Paulo State University-UNESP, Faculty of Dentistry of Araçatuba, Department of Dental Materials and Prosthodontics, Sao Paulo, Brazil.

- Corresponding author: Dr. Rodolfo Bruniera Anchieta Universidade Estadual Paulista Julio de Mesquita FilhoUNESP, Faculdade de Odontologia de Araçatuba. Departamento de Materiais Odontológicos e Prótese Rua José Bonifacio, 1193, Vila Mendonça, CEP: 16015-050

Phone/fax: 551836363290

E-mail: rodolfoanchieta2ahotmail.com

\section{INTRODUCTION}

All ceramic restorations, tooth-colored inlays, onlays, veneers and crowns based on silica content can be bonded to tooth substrate by adhesive resin cements. ${ }^{1-5}$ Basically, two techniques can be used to achieve this purpose: the conventional technique based on etching and rinse protocol, and the self-etching technique.

The conventional technique is a very sensitive method, requiring several sequential steps in or- 
der to achieve adequate bond strength between the ceramics and dental substrate, mainly for dentin. Failure or limitations in any step might impair the dentin hybridization and compromise the success rate of the restoration. ${ }^{6,7}$

In order to avoid such risks and the dental sensitivity regarding the conventional technique, the self-adhesive resin cements have been introduced for a one-step technique, avoiding the limitations and risks of each step of the conventional cementation. The dentin hybridization has been achieved and considered adequate. ${ }^{6}$

However, the differences in these resin luting cements, such as differences in chemical composition, filler rate, particle size, and initiation system can influence their bond strength to ceramic and tooth. ${ }^{4}$ Besides, the behavior of these luting agents under enamel and dentin is different. The bond strength on enamel has been considered inadequate in comparison to that one achieved by conventional technique. ${ }^{8}$

Thus, the objective of this study is to present a three-year follow-up of a case report in which the two cementation techniques were used for bonding 2 all-ceramic crowns and 2 laminate veneers in maxillary incisors.

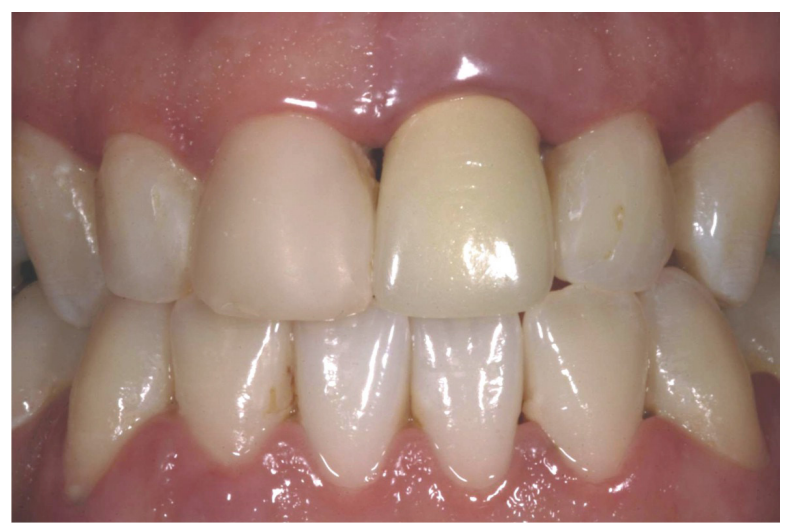

Figure 1. Frontal view of the anterior teeth.

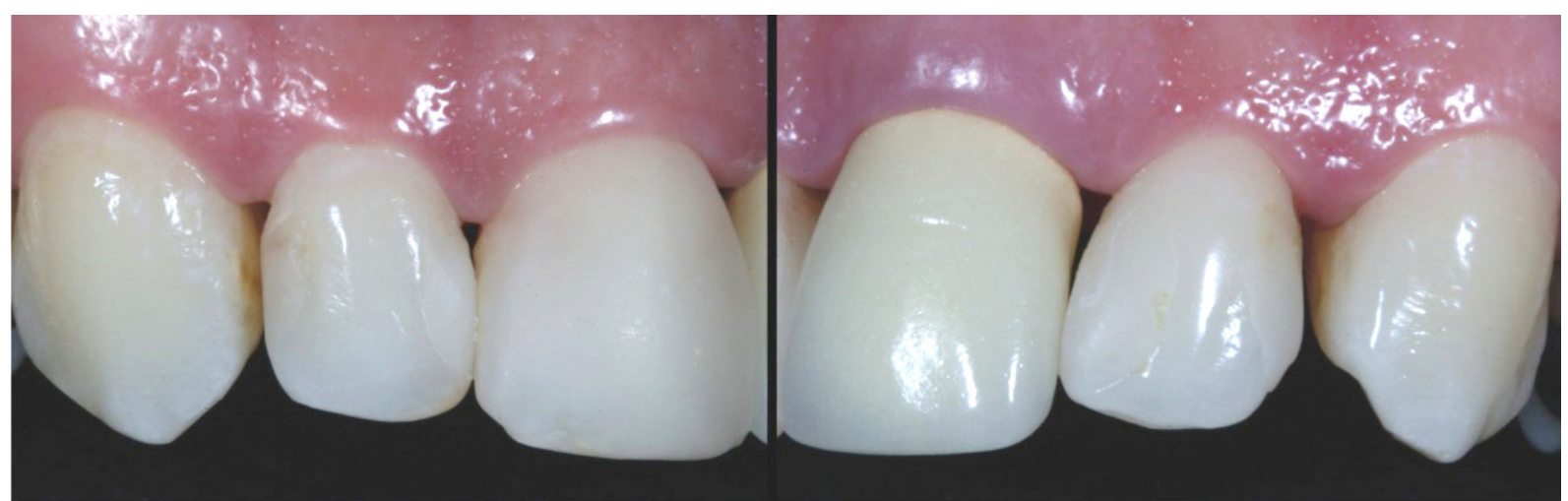

Figure 2. Note the larges class IV of composite resin (right and left lateral incisors) and the discolored margin of the metal-ceramic crown and grayish color in gingival region left central incisor.

\section{CASE REPORT}

A 41-year-old female, B.H.C, Caucasian, presented at the Sao Paulo State University, Araçatuba Dental School, complaining about her unattractive smile (Figure 1).

The clinical exam revealed an unsatisfactory metal ceramic crown in the left central incisor regarding marginal fit, color and anatomy, associated to grayish color in gingival region (metallic margin) and gingival inflammation. The right central and lateral incisors and the left lateral incisor presented Class III and IV resin composite restorations with inadequate anatomy and pigmentations at the tooth/restoration interface (Figure 2).

After clinical exam, impressions of maxillary and mandible arches were taken with polyvinylsiloxane (Express, 3M/ESPE, St. Paul, Minnesota USA) to obtain preliminary casts for diagnostic waxing from right to left lateral incisors and fabrication of 4 provisional crowns in acrylic resin (VipiCor, Sao Paulo, Brazil) (Figure 3).

The treatment planning was established according to the clinical exam and diagnostic waxing including 2 all-ceramic crowns (left central e lateral incisors) and 2 laminate veneers (right central and lateral incisors) based on ceramic system (IPS e.max Press, Ivoclar Vivadent, Schaan Liechtenstein).

Before the prosthetic treatment, a periodontal evaluation and prophylaxis were done for removing any signal of plaque accumulation or calculus. The metal ceramic crown was removed with a conical diamond bur (KOMET, Rock Hill, SC, UK). Two grooves were marked in the central portion of the crown reaching porcelain and metal in the buccal and lingual surfaces. These grooves were united in the incisal surface of the crown. 
After crown removal, a cast metal post and core was replaced by a glass fiber post (Reforpost, Angelus, Brazil). The esthetic core was built up with composite resin (Z350, 3M/ESPE, St. Paul, Minnesota USAl and cemented with self-adhesive

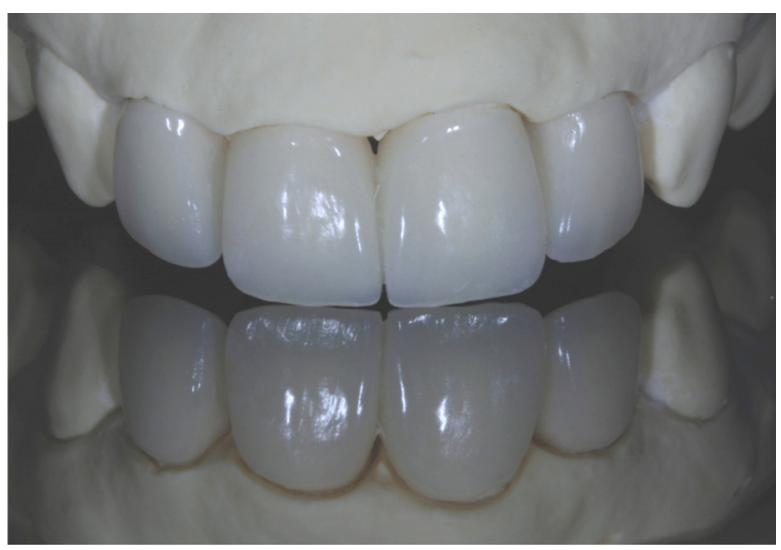

Figure 3. Aspect of 4 provisional crowns pressed in acrylic resin.

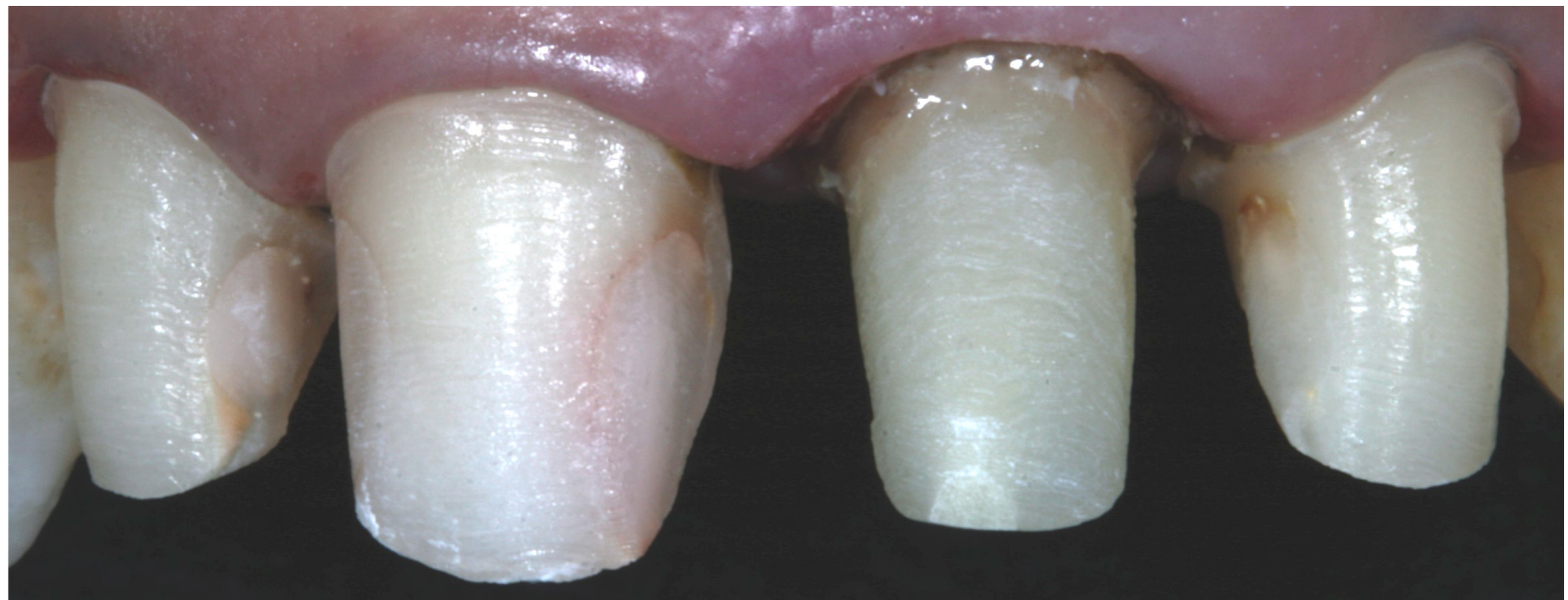

Figure 5. Finished dental reductions. The tooth's reductions were guided by a silicone index based on the diagnostic wax cast.

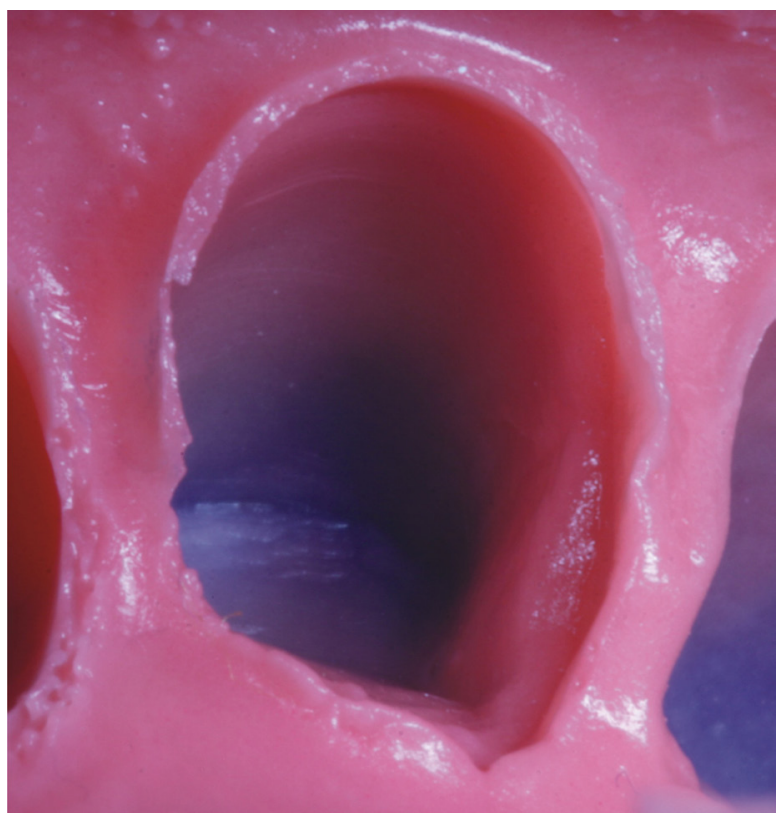

Figure 6. Aspect of the finished mold with a well defined and uniformity margin. resin luting cement RelyX Unicem (3M/ESPE, Seefeld, Germanyl (Figure 4).

Dental reduction was guided by a silicone index based on the diagnostic waxing cast.

After dental reduction (Figure 5), simultaneous

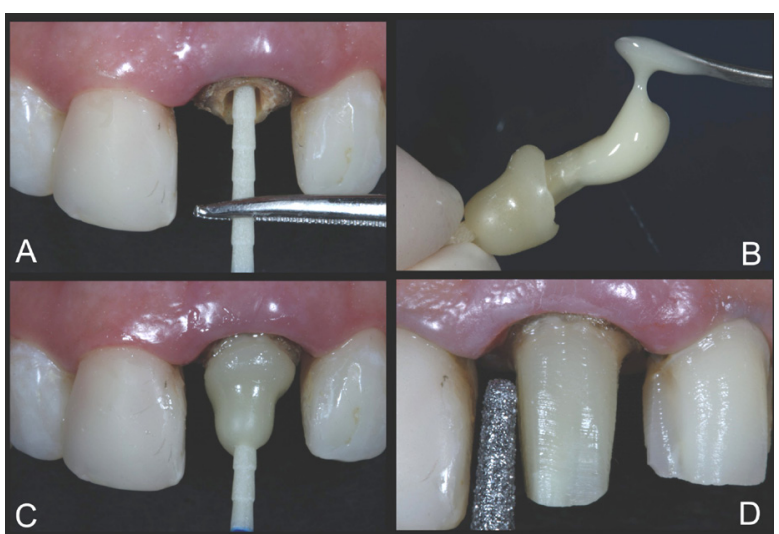

Figure 4. A. Testing of the insertion of the glass fiber post; B. Customized glass fiber post with composite resin and cementing with self-adhesive resin luting cement: C. Customized glass fiber post cemented. D. Dental reductions.

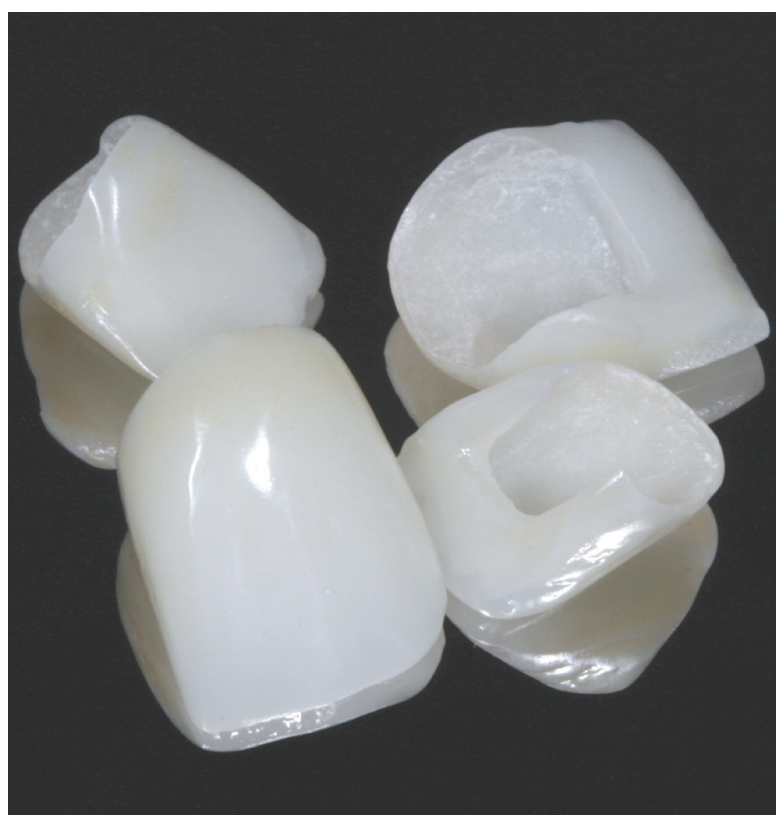

Figure 7. Ceramic crowns and laminate veneers ready for cementation. 
impression technique with retraction cord (double retraction cord techniquel was taken with polyether (Impregum, 3M/ESPE, St. Paul, Minnesota USA). The polyether was manipulated with the automatic mixing machine Pentamix 3 (3M/ESPE, St. Paul, Minnesota USAl and used due to its adequate hydrophilic behavior (Figure 6).

Then the provisional restorations were adjusted and cemented with temporary cement (RelyX
Temp, 3M/ESPE, St. Paul, Minnesota USA). The color selection was digitally recorded to be sent to dental laboratory.

After the restorations are ready (Figure 7) and clinical proof, the ceramic restorations were prepared for cementation. The internal surfaces of the ceramic restorations were etched according to the following steps: 1 st - conditioning with $10 \%$ hydrofluoric acid for 20 seconds; 2 nd - water rinse
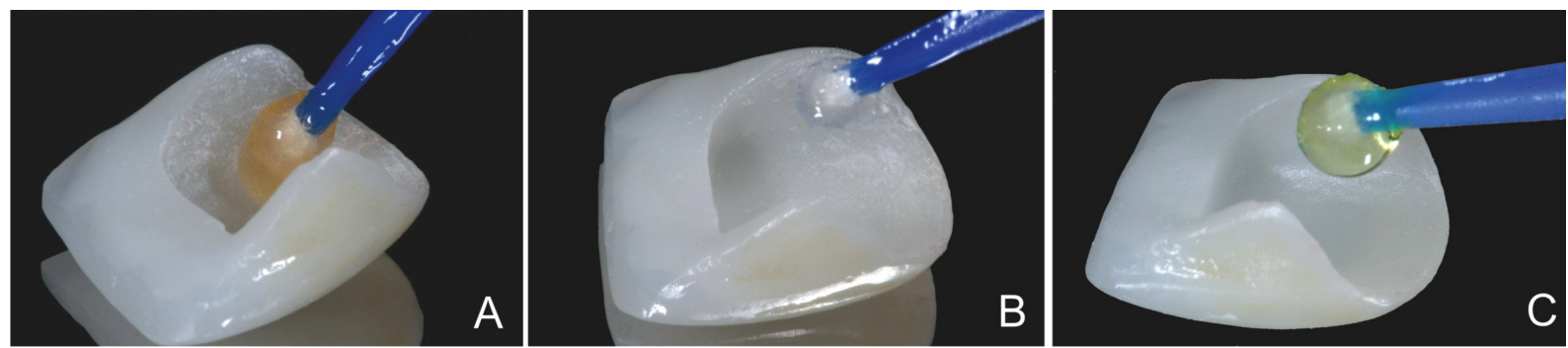

Figure 8. Etching of internal surface of the laminate veneers. A. Etching with a $10 \%$ hydrofluoric acid for 20 seconds; B. Application of silane for 1 minute; C. Application of bond resin.

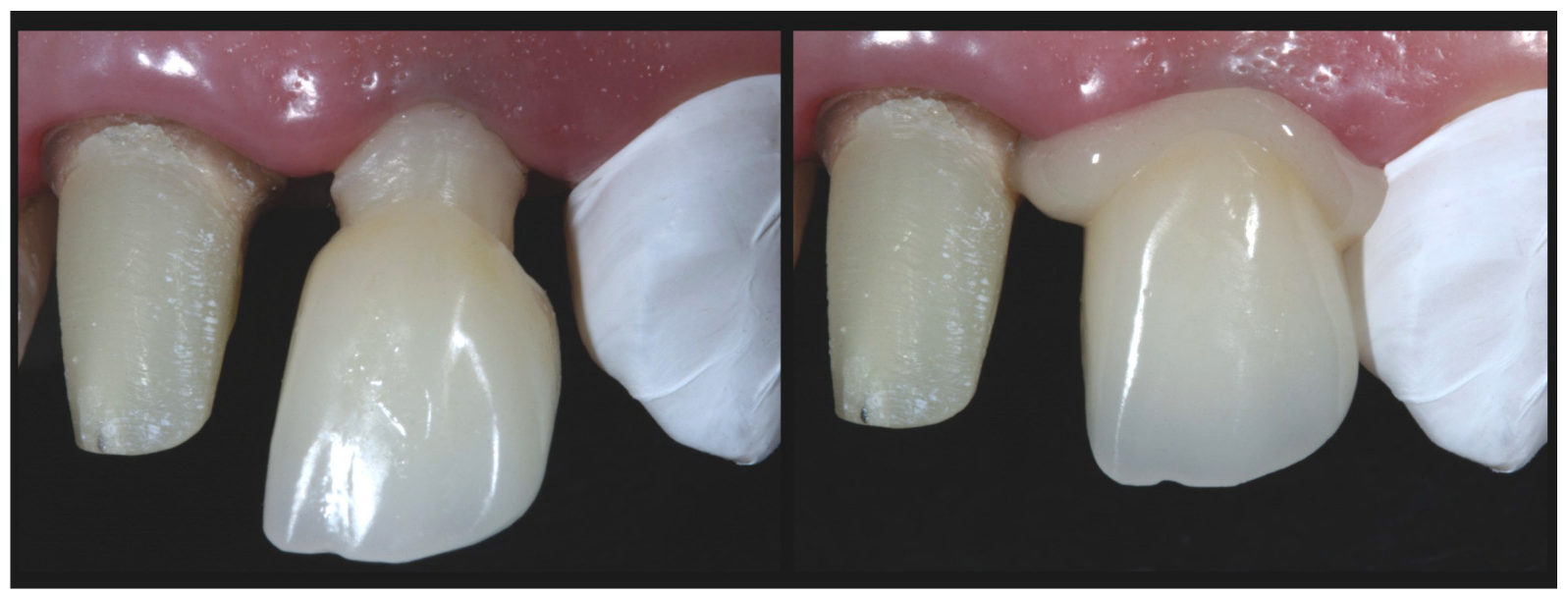

Figure 9. Self-adhesive resin cementation of total-ceramic crowns (left central and lateral incisors).

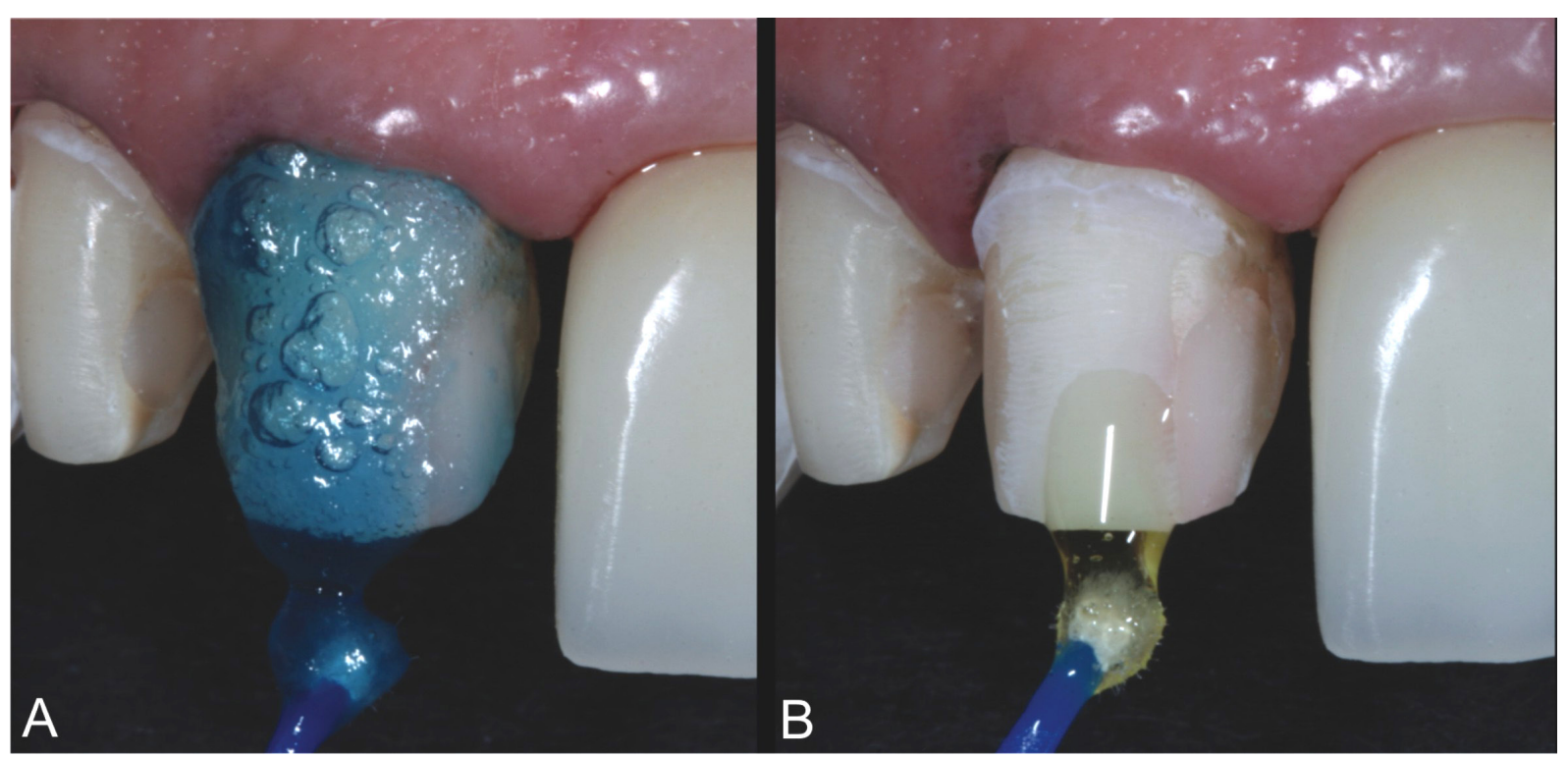

Figure 10. Hybridization of dental hard tissues; A. Phosphoric acid etching for 15 seconds; B. Application of a two step adhesive system. 
and air drying, 3rd - application of silane coupling agent for 1 minute; 4th - hot air drying; 5th - application of adhesive system and drying for removal of material excess (only for conventional technique); 6th - light polymerization of adhesive agent (only for conventional technique) (Figure 8).

The cementation procedures were initiated after gently cleaning all teeth preparations with pumice stone and water. The self-adhesive resin luting cement (RelyX Unicem, 3M/ ESPE, Seefeld, Germany) was used for full-coverage crowns (left cental and lateral incisor) while the conventional resin cement (RelyX ARC, 3M/ ESPE, Seefeld, Germany) was used for laminate veneers in which there was more enamel surface available.

The self-adhesive resin luting cement was manipulated according to the manufacturer's instruction and inserted in the full-coverage crown individually (Figure $9 A, B$ ). The excess was removed followed by polymerization during 40 seconds with a halogen light device (QHL75 Lite, Dentsply International, York, Pa.J.

For laminate veneers, the dental substrate was etched with phosphoric acid for 15 seconds, which was carried out in each right central and lateral incisor (Figure 10A).9,10 After water rinse and drying, the hybridization was achieved by using two step etch and rinse adhesive system (Figure 10B) (Adper Single Bond 2, 3M/ ESPE, Seefeld, Germanyl. The adhesive layer was polymerized during 15 seconds.

The conventional resin luting cement (RelyX ARC, 3M/ ESPE, St. Paul, USAl was manipulated according to the manufacturer's instruction and dispensed on the inner surface of the laminates for cementation. The laminates were individually placed in position (Figure 11).

It was noted the good appearance of restorations (Figure 12). After removal of material excess and retraction cord, the final adjustments of the restorations were taken as shown in the Figure 13, although a black space between the central incisors was present.

Five days after cementation, the health of gingival tissues surrounding restorations were observed, enhancing the integration between ceramics, gingival margin and lips. The esthetics results were very satisfactory (Figure 14). The quality of the restorations and the appearance of the gingival margin were maintained after two-year and threeyear follow-up. Note that black space between the central incisors was totally filled by papilla, contributing further to the aesthetic and harmony (Figures 15 and 16$)$.

\section{DISCUSSION}

The spectrum of materials for indirect restorations has been raised during recent decades. Ceramics have been used without any metallic support, mainly because of their superior esthetical properties. Silica-based ceramics require adhesive bond to tooth structures, which can help the mechanics of the ceramics. ${ }^{6,11-12}$

The integration between porcelain and cement has been reported to reinforce both substrates reducing the microleakage at the tooth-restoration interface. ${ }^{13,14}$

In the present report, two different techniques for bonding porcelain to the dental substrate were used: the conventional resin cementation and the self-adhesive resin cementation. Although there are many differences between both techniques, one aspect that might drive the choice is the dental substrate. Enamel substrate requires conventional technique for cementation once the bond strength of the self-adhesive resin cements on enamel is still problematic. ${ }^{15}$

It is important to highlight that the preparation of the right central and lateral incisors was kept on enamel while the dentin was reached for the left central and lateral incisors. According to these characteristics, the self-adhesive resin cement was indicated for the left central and lateral incisors while the conventional cementation was used for the right teeth.

The self-adhesive properties are claimed to be based upon functional phosphoric-acid methacrylates that demineralize the dentin, reacting with inorganic fillers ( $72 \mathrm{wt} \%$ ), and infiltrate the tooth substrate to create the hybrid layer. This characterizes also the micromechanical retention. Secondary reactions have been suggested to provide chemical adhesion to hydroxyapatite. ${ }^{6}$ The basic inorganic fillers are able to undergo a cement reaction with the phosphoric-acid methacrylates. The dominant setting reaction starts with free radical polymerization, which can be initiated either by light or by a redox system (dual-curing composite materials). ${ }^{6}$ Water released from the setting reaction is thought to play a role in its neutralization, as well anionic ions, for raising the $\mathrm{pH}$ value from 1 to $6 .{ }^{16}$ 


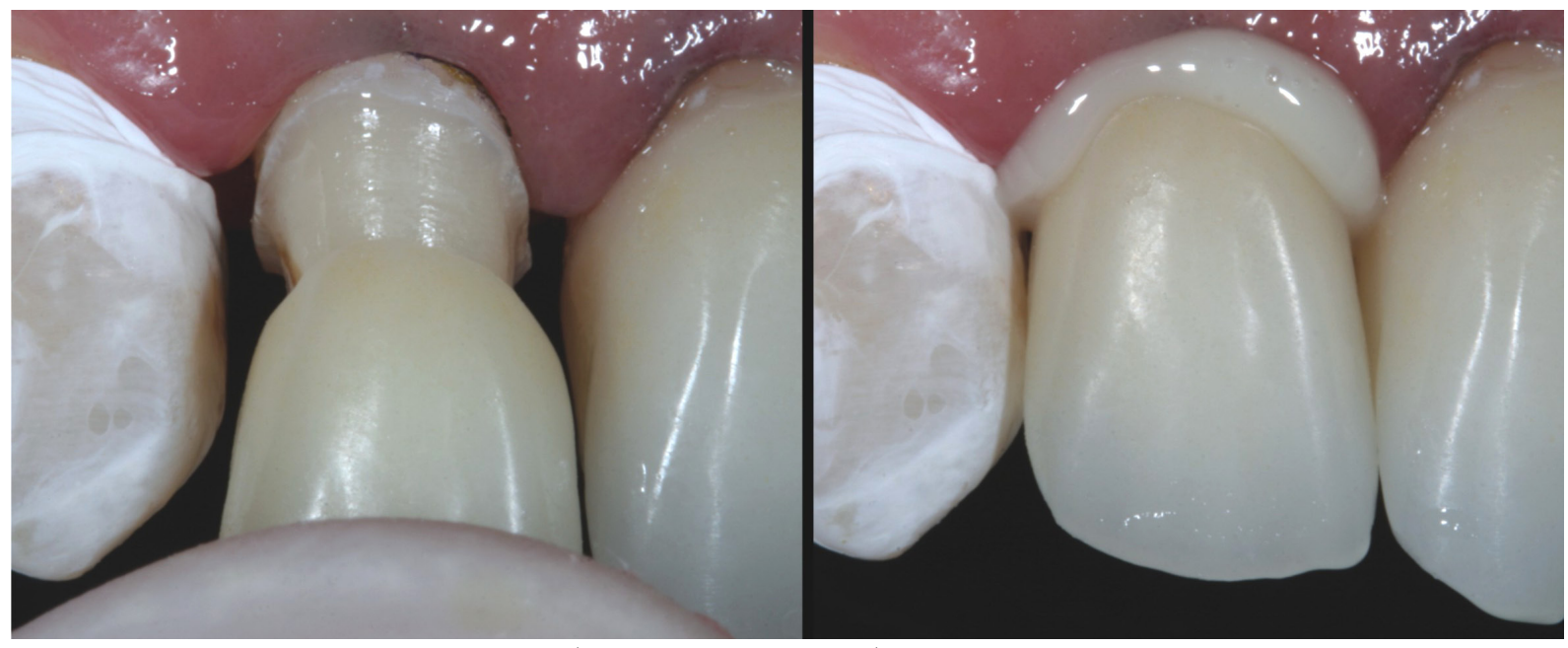

Figure 11. Convention resin cementation of laminate veneers (right central and lateral incisors).
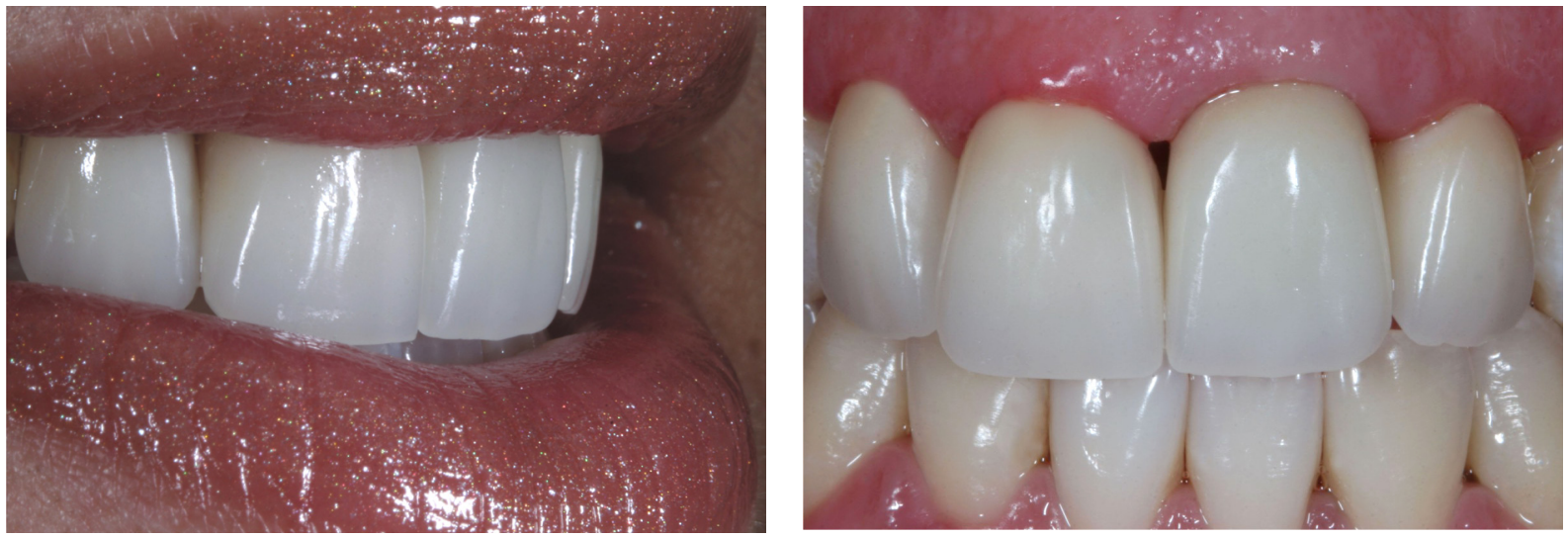

Figure 12. A beautiful smile just after cementation with the incisal margins accom-

Figure 13. Immediately after the cementation it's possible to note the good appearpanying the labial line. ance of the restorations. A black space that was not filled by the papillae was present.

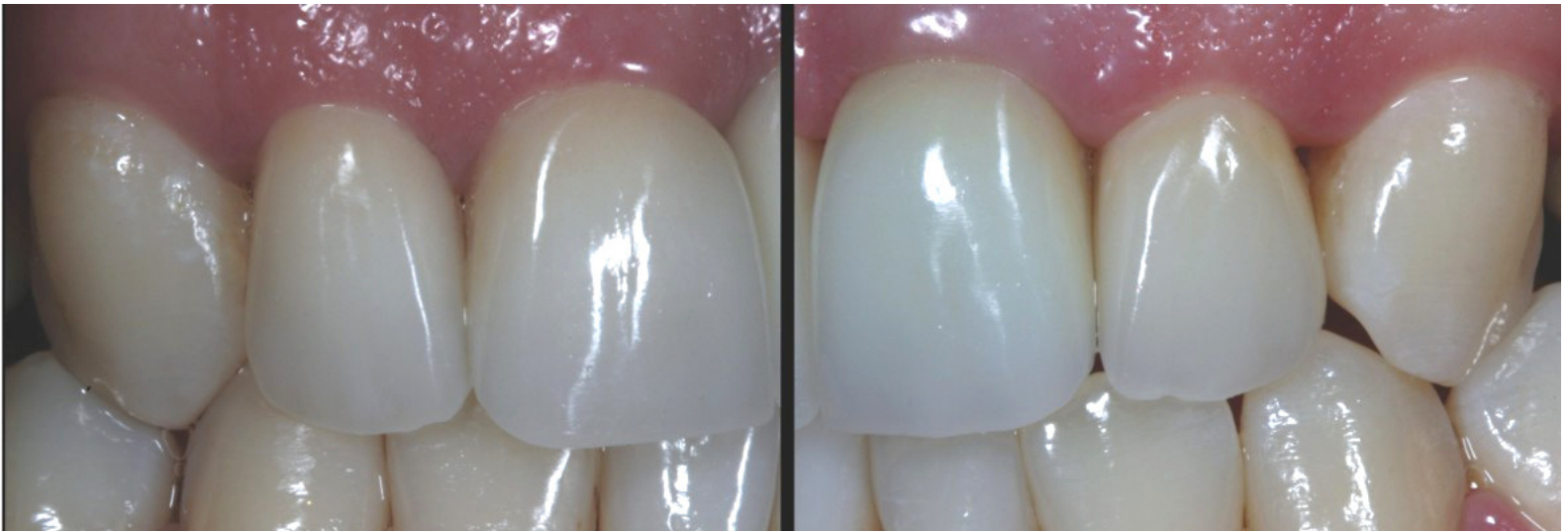

Figure 14. Aesthetics of dental tissues and gingival margins after 5 days.

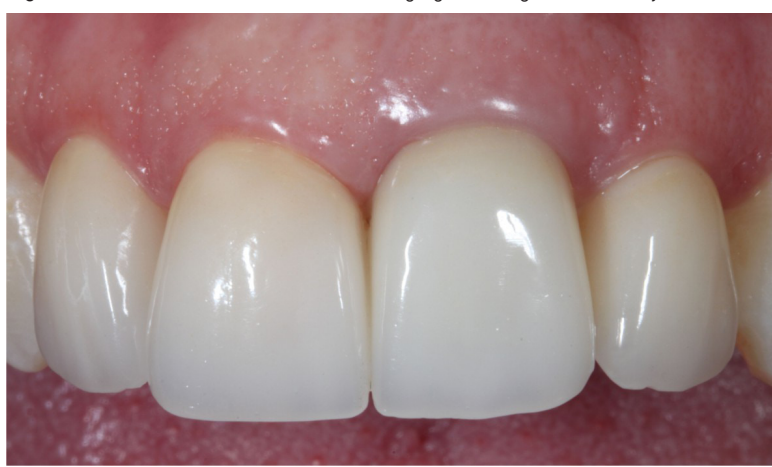

Figure 15. The gingival tissues are healthy and the quality of restorations was maintained after two-year follow-up.

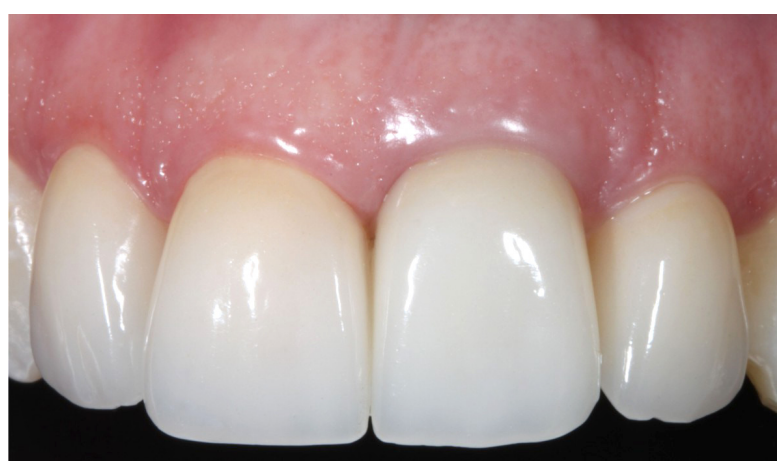

Figure 16. After three years follow-up it is observed that the black space between the central incisors was complete filled by the papillae and the esthetics and quality of restorations were maintained. 
Others authors claimed that without any conditioning, the self-adhesive cement RelyX Unicem (3M/ ESPE, Seefeld, Germany) showed improved sealing of dentin at the cervical margin when compared to a conventional resin cement. ${ }^{8}$ The RelyX Unicem showed bond strength to dentin not statistically different from the other resin based luting materials. ${ }^{6,15}$

The conditioning of inner surfaces of the ceramic restorations was performed in the present study with $10 \%$ hydrofluoric acid for 10 seconds, followed by silane application, to improve bond results. ${ }^{17,18}$

The conditionings of the ceramics were carried out since literature states that the lack of ceramic conditioning previously to cementation results in low bond strength between cement and ceramic. ${ }^{4,19}$ This is in agreement with other authors that demonstrated proper bonding between these substrates as a result of porcelain conditioning and silanization. ${ }^{20-22}$

In this context, the application of a silane coupling agent to the pretreated ceramic surface provides a chemical covalent and hydrogen bond ${ }^{23}$ and it is a major factor for a sufficient resin bond to silica-based ceramics. ${ }^{24}$ Silanes are bifunctional molecules that bond silicone dioxide with the $\mathrm{OH}$ groups on the ceramic surface. They also have a degradable functional group that copolymerizes with the organic matrix of the resin. ${ }^{23}$

For the teeth with preparation on enamel, the laminates were cemented with the conventional technique using RelyX ARC (3M/ ESPE, Seefeld, Germany).

In addition, the proper enamel hybridization resulted from conditioning with phosphoric acid for 15 seconds $9,10,25$ followed by application of onebottle adhesive system (Adper Single Bond 2, 3M/ ESPE, Seefeld, Germanyl and light polymerization during 15 seconds. Then, the porcelain restorations were cemented. ${ }^{21}$

The conventional technique was used in this case since the self-adhesive cements (Unicem) may not be the ideal material for luting inlays and partial crowns, where a considerable enamel surface area is present. ${ }^{6}$ So, many authors ${ }^{6}$ showed that the bond strength of Unicem to enamel was statistically lower than all other luting resins and it was also observed greater leakage at the enamel interface with this cement without any previous conditioning. ${ }^{8}$ These results suggest an insufficient etching ability of the cement to the smear layer covering enamel and, therefore, the lack of development of adequate micromechanical retention.

According to this, conventional adhesion procedures are indicated for enamel using adhesive systems for bonding between tooth and cement due to proper bond strength and marginal sealing. 26,27

So, the procedures based on protocols established by literature and clinical experience provided patient's satisfaction regarding the immediate result of the restorations maintained up to three-year follow-up. No sign of misfit, leakage or staining in tooth/cement/ceramic interface was clinically observed after three years. In addition, health of gingival tissue surrounding restorations was noticed and the restorations were harmonically integrated with soft tissues. ${ }^{28}$

\section{CONCLUSIONS}

Conventional and self-adhesive resin cements are appropriate for cementation of all-ceramic restorations. However, the proper indication depends on the dental substrate available after preparation. The use of both cements in the same clinical case has been shown to be adequate to achieve satisfactory esthetic and functional results after three year follow up.

\section{REFERENCES}

1. Manhart J, Scheibenbogen-Füchsbrunner A, Chen HY, Hickel R. A 2-year clinical study of composite and ceramic inlays. Clin Oral Investig 2000;4:192-198.

2. Mitchell CA, Abbariki M, Orr JF. The influence of luting cement on the probabilities of survival rate and modes of failure of cast full-coverage crowns. Dent Mater 2000;16:198206.

3. Peumans $M$, Van Meerbeek B, Lambrechts $P$, Vanherle G. Porcelain veneers: review of the literature. J Dent 2000;28:163-177.

4. Peumans M, Hikita K, De Munck J, Van Landuyt K, Poitevin A, Lambrechts P \& Van Meerbeek B. Bond durability of composite luting agents to ceramic when exposed to longterm thermocycling. Oper Dent 2007;32:372-379.

5. Chen Y-W, Raigrodski AJ. A conservative approach for treating young adult patients with porcelain laminate veneers. J Esthet Restor Dent 2008;20:223-238. 
6. Abo-Hamar SE, Hiller KA, Jung H, Federlin M, Friedl KH \& Schmalz $G$. Bond strength of a new universal self-adhesive resin luting cement to dentin and enamel. Clin Oral Investig 2005;9:161-167.

7. Pospiech P. All-ceramic crowns: bonding or cementing? Clin Oral Investig 2002;6:189-197.

8. Ibarra G, Johnson GH, Geurtsen W, Vargas MA. Microleakage of porcelain veneer restorations bonded to enamel and dentin with a new self-adhesive resin-based dental cement. Dent Mater 2007;23:218-225.

9. Yazici AR, Celik C, Özgünaltay G, Dayangaç B. Bond strength of different adhesive systems to dental hard tissues. Oper Dent 2007;32:166-172.

10. Pivetta MR, Moura SK, Barroso LP, Lascala AC, Reis A, Loguercio $\mathrm{AD}$, Grande $\mathrm{RH}$. Bond strength and etching pattern of adhesive systems to enamel: effects of conditioning time and enamel preparation. $J$ Esthet Restor Dent 2008;20:322-336.

11. Burke FJ. The effect of variations in bonding procedure on fracture resistance of dentin-bonded all-ceramic crowns. Quintessence Int 1995; 26:293-300.

12. Burke FJ, Fleming GJ, Nathanson D, Marquis PM. Are adhesive technologies needed to support ceramics? An assessment of the current evidence. J Adhes Dent 2002;4:722.

13. Dietschi D, Maeder M, Meyer JM, Holz J. In vitro resistance to fracture of porcelain inlays bonded to tooth. Quintessence Int 1990;21:823-831.

14. Burke FJ, Watts DC. Fracture resistance of teeth restored with dentin-bonded crowns. Quintessence Int 1994;25:335340.

15. De Munck J, Vargas M, Van Landuyt K, Hikita K, Lambrechts P. Van Meerbeek B.. Bonding of an auto-adhesive luting material to enamel and dentin. Dent Mater 2004;20:963991.

16. Behr M, Rosentritt M, Regnet T, Lang R, Handel G. Marginal adaptation in dentin of a self-adhesive universal resin cement compared with well-tried systems. Dent Mater 2004;20:191-197.

17. Chen JH, Matsumura H, Atsuta M. Effect of etchant, etching period, and silane priming on bond strength to porcelain of composite resin. Oper Dent 1998;23:250-257.

18. Sorensen JA, Engelman MJ, Torres TJ, Avera SP. Shear bond strength of composite resin to porcelain. Int J Prosthodontics 1991;4:17-23.

19. Kumbuloglu O, Lassila LV, User A, Toksavul S, Vallittu PK. Shear bond strength of composite resin cements to lithium disilicate ceramics. J Oral Rehabil 2005;32:128-133.
20. Piwowarczyk A, Lauer HC, Sorensen JA. In vitro shear bond strength of cementing agents to fixed prosthodontic restorative materials. J Prosthetic Dent 2004;92:265-273.

21. Reich SM, Wichmann M, Frankenberger R, Zajc D. Effect of surface treatment on the shear bond strength of three resin cements to a machinable feldspatic ceramic. $J$ Biomed Mater Res Part B Applied Biomater 2005;74:740-746.

22. Soares CJ, Soares PV, Pereira JC, Fonseca RB. Surface treatment protocols in the cementation process of ceramic and laboratory-processed composite restorations: a literature review. J Esthet Restor Dent 2005;17:224-235.

23. Blatz MB, Sadan A, Kern M. Resin-ceramic bonding: a review of the literature. J Prosthetic Dent 2003;89:268-274.

24. Frankenberger R, Kramer N, Sindel J. Repair strength of etched vs silicacoated metal-ceramic and all-ceramic restorations. Oper Dent 2000;25:209-215.

25. Swift EJ, Perdigao J, Heymann HO. Bonding to enamel and dentin: a brief history and state of the art. Quintessence Int 1995;26:95-110.

26. Deliperi S, Bardwell DN, Wegley C. Restoration interface microleakage using one total-etch and three self-etch adhesives. Oper Dent 2007;32:179-184.

27. Hikita K, Van Meerbeek B, De Munck J, Ikeda T, Van Landuyt K, Maida T, Lambrechts P \& Peumans M. Bonding effectiveness of adhesive luting agents to enamel and dentin. Dent Mater 2007;23:71-80.

28. Chu SJ, Tan J H-P, Stappert CFJ, Tarnow DP. Gingival zenith positions and levels of the maxillary anterior dentition. Esthet Restor Dent 2009;21:113-121. 